\title{
The Development of Under the Volley Passing Material Learning Models in Elementary School Students in Medan City
}

\author{
Ayumi Adetya, Dr. Amir Supriadi, S.Pd,M.Pd, Dr. Tarsyad Nugraha, M.Kes \\ Program Pascasarjana, Universitas Negeri Medan, \\ Medan, Indonesia \\ Ayumiadetya17@gmail.com
}

\begin{abstract}
These studies are developmental studies that aim to produce learning model products. The subjects of the small group trial were 24 students of Public Elementary School 060927 Medan, the subjects of the large group trial consisted of 44 students from the Public Elementary School 060928 Medan. The ultimate goal of this development research is to produce a product in the form of a learning model in the material passing under volleyball, so that it can help the learning process so that student learning can be more effective, efficient, and interesting. In particular there are a number of objectives including: 1) Developing and implementing learning models in elementary school volleyball learning. 2) To obtain in-depth information about learning models in improving volleyball learning outcomes on volleyball. 3) Obtain empirical data about effectiveness, efficiency and attractiveness as a result of developing a learning model in volleyball learning.
\end{abstract}

Keywords: Learning Model, Lower Passing, Volleyball.

\section{INTRODUCTION}

Physical education in sports and health in schools is important for overall education. The existence of physical sports education and health in schools not only improves the health and physical fitness of children, but provides experiences in the fields of cognitive, affective, psychomotor and physical for children. Therefore the implementation of sports and health physical education needs to be dealt with seriously and also pay attention to the existence of facilities and infrastructure that can support the condition of conducive learning. To achieve the success of physical sports and health education there are several factors that affect, among others: teachers, students, facilities and infrastructure and curriculum.

With the existence of Sports Physical Education and Health in schools proves that sport is an element of coaching that must improve the quality of human resources to build physical and spiritual health, foster discipline and sportsmanship and increase the development of sports achievements that can enhance nationalism that needs to be promoted. The main assessment of learning physical sports education and health is how to make children happy and happy in carrying out motion activities, so that the level of involvement and intensity of motion is achieved and realized through learning activities designed and presented. One of the physical education learning activities is studying volleyball material.

Volleyball games are team games played by two teams and each team consists of six players. Volleyball is a complex game that is not easy for everyone. According to Suharno (1991: 1) volleyball games are team sports played by two teams, each team consists of six players on the playing field measuring $18 \mathrm{~m} \times 9 \mathrm{~m}$. The aim of the player in playing is to drop the ball as fast as possible on the opponent's field over the net with the body of the waist up on condition that the ball bounces perfectly in accordance with the rules. Therefore the volleyball game requires a correct and appropriate training model so that in the volleyball game it produces a perfect game, because imperfect movements will cause wrong movements and result in the game not going well. In the volleyball game consists of basic techniques namely passing, service, block and smash.

The basic volleyball technique is a very important element in volleyball, without mastering good basic techniques, the game cannot be played perfectly. The basic volleyball technique has a very important role before the players increase their abilities to higher skills. According to Winarno and Sugiono (2011: 40), in general, the basic techniques of volleyball can be divided into four components which include: bottom and top service techniques, bottom and top passing, smash, and block.

Passing is one of the basic techniques in volleyball. Good passing mastery is the main capital in volleyball. For this reason, variations in upper passing and lower passing are needed to improve the passing skills of volleyball. Based on the results of observations, giving variations in passing practice is still less varied.

Researchers encountered problems in physical education teaching and learning activities in several elementary schools in Medan where there was material whose learning was still standard, namely in volleyball learning. There are a number of problems that I have encountered in physical education and sports teaching and learning activities in volleyball material in 
some of these elementary schools, the problem is that sports and health physical education teachers in volleyball learning materials have no game modifications that make students more motivated, because it uses the actual equipment and regulations.

Based on the needs analysis distributed to 20 elementary school students in Medan, it can be found that there were 13 people who answered they did not like volleyball material, then 15 students answered that learning volleyball material did not use assistive devices. Of the 12 students answered that the passing down material was difficult to do. And the last issue is that 11 students answered that volleyball material was not carried out with the concept of the game. The results of the analysis of student needs were used as a reference for gathering information for the development of a lower passing learning model in elementary school volleyball games.

From the results of the preliminary study also, researchers found several problems in teaching and learning activities (KBM) physical education in sports and health in elementary school, among others: 1) Rules and equipment used have not been modified (standard), and this is not in accordance with the stages of student growth. 2) Physical and Physical Education Teachers lack the courage to try to modify a more varied volleyball game. 3) Lack of evaluation from the Physical and Health Physical Education teacher

The results of interviews with physical education teachers on July 4, 2019 that indeed teachers rarely do the learning concepts of games for obscene material, the game is only carried out in the standard rules such as the original game. And the teacher also never modifies the tool to be simpler.

Based on the description above, it is expected that sports and health physical education teachers will create various modifications to volleyball games that are more varied and not monotonous. The aim is to attract students to be more active and anticipate the boredom and saturation that is often experienced by students in following the learning process of Physical Sports and Health Education.

Based on this, researchers also found the idea to create a model of learning to pass under-volleyball material for elementary school children. Learning models are learning activities carried out by two actors, namely teachers and students. Teacher behavior is teaching and student behavior is learning. The contents contained in the learning model are in the form of teaching strategies used to achieve instructional goals. Examples of teaching strategies that teachers usually apply when teaching and learning are classroom management, grouping students, and the use of teaching aids. In learning that places the role of the teacher as the center of the process, among other things the teacher acts as a source of information, class managers, and becomes a figure to be emulated. Interesting and varied learning models will have an impact on the interests and motivations of students in following the teaching and learning process in the classroom.
Based on the description of the problem above, the researcher conducted a development research entitled "Development of Learning Materials Model Passing Under Volleyball in Elementary Students in Medan City". The product in this study is a module containing a lower passing learning model for elementary school children.

\section{METHOD}

In the study of developing learning models in volleyball under-passing material for elementary students in Medan City in 2019 this is a process used to develop and validate learning products. Borg \& Gall (1983: 776) put forward a series of steps to be taken in this approach including 10 general steps, such as the following:

1. Research and information collecting: study of literature relating to the problems studied, and preparation to formulate a research framework.

2.Planning: formulating skills and expertise related to the problem, determining the objectives to be achieved at each stage, and if possible / needed to carry out limited feasibility studies.

3. Develop preliminary form of product; developing the initial form of the product to be produced, preparation of supporting components, preparing guidelines and manuals, and evaluating the feasibility of supporting tools. these steps include: (1) Determining the product design to be developed (hypothetical design), (2) determining the research facilities and infrastructure needed during the research and development process, (3) determining the stages of implementation of design tests in the field; (4) determine the task description of the parties involved in the study.

4. Preliminary field testing: conduct initial field trials on a limited scale. by involving 6 - 12 subjects. In this step data collection and analysis can be done by interview, observation or questionnaire. This step is a limited product test which includes: (1) conducting an initial field test on product design, (2) being limited, both the design substance and the parties involved, and (3) the initial field test is carried out repeatedly so that obtained a decent design, both substance and methodology.

5. Main product revised: make improvements to the initial product produced based on the results of the initial trial. This improvement is very likely to be carried out more than once, according to the results shown in the limited trial, so that the main product (learning model) is obtained which is ready for a wider trial. Revision II is a revision based on the opinions, difficulties, and desires of the users. Revised field tests are limited which are improvements to the learning model or design based on limited field testing. Revision III is a revision based on the opinions and input of experts.

6. Main field testing: the main trial involving all students. (1) conduct an initial field test on product design, (2) be limited in nature, both the design substance and the parties involved, and (3) the initial field test is carried out 
repeatedly to obtain a proper design, both substance and methodology.

7. Operational product revision: make improvements / improvements to the results of wider trials, so that the products developed are already operational media designs that are ready to be validated. Revised Broader Field Test Results: this step is the second improvement after extensive field testing of the first field test.

8. Operational field testing: validation test of the operational media that has been produced. Final Revision of Feasibility Test Results. This step will further refine the product being developed which includes (1) testing the effectiveness and adaptability of the learning model on the material passing under volleyball. (2) test the effectiveness and reliability of the learning model on the material passing under volleyball involving prospective product users, and (3) the results of field testing are obtained design learning models that are ready to be applied, both in terms of substance and methodology.

9. Final product revisio: make final improvements to the learning model developed to produce the final product. This step will further refine the product being developed.

10. Dissemination and implementation: disseminating the product / model of learning developed. Reports on the results of $\mathrm{R} \& \mathrm{D}$ through scientific forums, or through mass media. Product distribution must be done after going through quality control.

\section{RESULTS AND DISCUSSION}

This research is a development research that aims to produce learning model products. In particular there are a number of objectives including:

1. Develop and implement learning models in elementary school volleyball learning.

2. To obtain information in depth about the learning model in improving volleyball learning outcomes on volleyball.

3. Obtain empirical data on effectiveness, efficiency and attractiveness as a result of developing a learning model in volleyball learning.

The ultimate goal of this development research is to produce a product in the form of a learning model in the material passing under volleyball, so that it can help the learning process so that student learning can be more effective, efficient, and interesting.

\section{REFERENCES}

[1] Aip, Syarifuddin. 1991. Volleyball. Ministry of Education and Culture Directorate General of Higher Education Project Development of Educators.

[2] Borg. W. R \& Gall, M. D. 1983. Educational Research An Introduction. New York: Longman.

[3] Hamzah. B. Uno (2007). Learning Model (Creating a Creative and Effective Teaching and Learning Process). Jakarta: Bumi Aksara.

[4] Sugiyono. 2010. Educational Research Methods Strong, Qualitative, and R \& D Approaches Bandung: CV. Alfabeta.

[5] Rusli Lutan. 2000. Teaching and Learning Strategies Penjaskes. Department of Education and Culture Directorate General of Primary and Secondary Education Section of D-III Equivalent SLTP Teacher Training Project.

[6] Rusli Lutan. 2001. Measuring and Evaluating Assessment. Department of Education and Culture Directorate General of Primary and Secondary Education Section of D-III Equivalent SLTP Teacher Training Project. 